\title{
Effective X-ray elastic constant of cast iron
}

\author{
Mattias Lundberg ${ }^{1, \star}$ (D), Jonas Saarimäki ${ }^{1}$ (D), Johan J. Moverare ${ }^{1}$ (D), and Ru Lin Peng ${ }^{1}$ (D) \\ ${ }^{1}$ Department of Management and Engineering, Division of Engineering Materials, Linköping University, 58183 Linköping, Sweden
}

Received: 24 April 2017

Accepted: 4 September 2017 Published online:

12 October 2017

(C) The Author(s) 2017. This article is an open access publication

\begin{abstract}
$X$-ray diffraction is a non-destructive method used for strain measurements in crystalline materials. Conversion of strain to stress can be achieved using the X-ray elastic constants (XEC), $s_{1}$ and $1 / 2 s_{2}$. The $\sin ^{2} \psi$ method was used during in situ loading to determine $\mathrm{XEC}$ for flake, vermicular, and spherical graphite iron. A fully pearlitic steel was used as reference. Uniaxial testing was conducted on the cast iron to create a homogeneous strain field, as well as four-point bending in both tension and compression due to the tension/compression asymmetry. The commonly used XEC value $1 / 2 S_{2}=5.81 \times 10^{-6} \mathrm{MPa}^{-1}$ is theoretically derived from an $\alpha$-Fe single crystal. When investigating materials that contain ferrite, such as polycrystalline cast iron, this value is not accurate. Determination of an effective XEC for polycrystalline cast iron yields a better correlation between the measured microstrains and the properties observed on a macroscopic scale. The need for an effective XEC is evident, especially when it comes to model validation of, for example, casting simulations. Effective XEC values have been determined for flake, vermicular, and spherical graphite iron. The determined value is lower than the theoretical value.
\end{abstract}

\section{Introduction}

Laboratory X-rays are used to measure surface residual stresses (RS) in polycrystalline metallic materials. $\mathrm{X}$-ray diffraction (XRD) is a non-destructive, reliable method to measure RS. The stress distribution described by the two principal stresses $\sigma_{1}$ and $\sigma_{2}$ that exist in the plane of the surface, assuming no stresses perpendicular to the surface $\sigma_{3}=0$, is illustrated in Fig. 1 .

However, a stress component exists perpendicular to the surface due to the Poisson's ratio, $v$, contraction caused by the two principal stresses. It is therefore possible to establish the expression for the strain, $\varepsilon_{\varphi \psi}$, defined by the two angles $\varphi$ and $\psi$ seen in Fig. 1 according to:

$$
\begin{aligned}
\varepsilon_{\Phi \Psi}= & {\left[\frac{1+v}{E}\left(\sigma_{1} \cos ^{2} \Phi+\sigma_{2} \sin ^{2} \Phi\right) \sin ^{2} \Psi\right] } \\
& -\left[\frac{v}{E}\left(\sigma_{1}+\sigma_{2}\right)\right],
\end{aligned}
$$

where $E$ is the Young's modulus.

When $\psi$ is $90^{\circ}$, the strain vector lies in the plane of the surface, giving the surface stress component $\sigma_{\varphi}$ according to:

$\sigma_{\Phi}=\left(\sigma_{1} \cos ^{2} \Phi\right)+\left(\sigma_{2} \sin ^{2} \Phi\right)$.

The original version of this article was revised due to a retrospective Open Access order.

Address correspondence to E-mail: mattias.lundberg@liu.se 


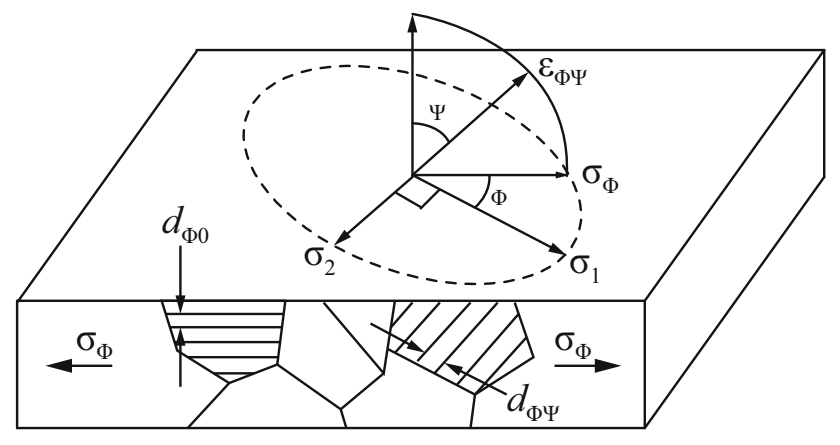

Figure 1 Plane stress elastic model.

Substituting Eq. 2 into Eq. 1 yields the surface strain at an angle $\varphi$ away from the principal stress $\sigma_{1}$ according to:

$\varepsilon_{\Phi \Psi}=\left[\frac{1+v}{E} \sigma_{\Phi} \sin ^{2} \Psi\right]-\left[\frac{v}{E}\left(\sigma_{1}+\sigma_{2}\right)\right]$.

Since $d_{\varphi \psi}$ is the spacing between the lattice planes measured in the directions defined by $\varphi$ and $\psi$, the strain can be expressed according to:

$\varepsilon_{\Phi \Psi}=\frac{d_{\Phi \Psi}-d_{0}}{d_{0}}$.

For the non-expert reader, we have now reached the point where it is possible to describe the relationship between the lattice spacing and the biaxial surface stresses, according to:

$$
\begin{aligned}
d_{\Phi \Psi}= & {\left[\left(\frac{1+v}{E}\right)_{(h k l)} \sigma_{\Phi} d_{0} \sin ^{2} \Psi\right] } \\
& -\left[\left(\frac{v}{E}\right)_{(h k l)} d_{0}\left(\sigma_{1}+\sigma_{2}\right)+d_{0}\right],
\end{aligned}
$$

where $\left(\frac{1+v}{E}\right)_{(h k l)}=1 / 2 s_{2}$ and $\left(\frac{v}{E}\right)_{(h k l)}=s_{1}$ which are the $X$-ray elastic constants (XEC) for the measured lattice spacing $d_{h k l}$.

Residual stresses can be measured utilizing the $\sin ^{2} \psi$ method. Using the $\sin ^{2} \psi$ method is beneficial since the unstressed lattice spacing $\left(d_{0}\right)$ can be unknown. Instead of $d_{0}, d \perp$ is utilized and is taken from when the specimen is perpendicular to the diffraction plane assuming plane stress condition at the surface, resulting in errors $<0.1 \%$ for RS determination [1-4]. Substituting $d_{0}$ with $d \perp$ yields a negligible error for the elastic strains, $<0.1 \%$, difference between the true $d_{0}$ and $\mathrm{d}$ at any $\psi$ angle. Since $d_{0}$ is a multiplier to the slope in the $d$ versus $\sin ^{2} \psi$ plot, the total error introduced by this assumption in the final stress value is $<0.1 \%$, which is negligible compared to the error introduced by other sources.
Conversion of strain to stress can be achieved using the XEC $s_{1}$ and $1 / 2 s_{2}$. The commonly used XEC values $s_{1}=-1.26 \times 10^{-6} \mathrm{MPa}^{-1}, \quad 1 / 2 s_{2}=5.81 \times 10^{-6}$ $\mathrm{MPa}^{-1}$ are theoretically derived from an $\alpha$-Fe single crystal using the Voigt model [1]. Deformation and alloying elements can affect the XEC by resulting in a higher or lower value [3]. Hauk and Wolfstieg [5] suggested that the XEC value decreases with increasing tensile surface stresses in grey cast iron. They also showed that different values should be used for tensile and compressive RS. It is commonly assumed that the XEC for grey cast iron can be used for all types of cast iron. In this work, a test series was developed in order to derive more accurate XEC for flake, vermicular, and spherical graphite iron, in order to show and prove that this might not give the most accurate results. The effective XEC for the three different cast iron specimens were determined under different testing conditions. Due to the material tension/compression asymmetry and nonlinear elastic behaviour, both uniaxial and four-point bending were utilized. How XEC varies in cast iron needs more investigation, as well as XEC determination in both tension and compression.

\section{Experimental procedures}

Uniaxial XEC determination was conducted using ASTM E1426-98 as a guideline, fulfilling the majority of recommendations, as cast iron does not exhibit a linear elastic behaviour. For four-point bending, XRD data collection cycles were reduced to two, but retrieving more data points than that recommended in ASTM E1426-98. To remove the effect of surface stresses and strain hardening, all samples were carefully polished. To verify that no surface stresses were still present or induced by the cutting and/or polishing, RS measurements were taken post-polishing before preloading. Preloading was conducted in order to homogenize the stress state of the sample. All samples were preloaded using fifteen cycles. Three types of cast iron were used: flake, vermicular, and spherical graphite iron. An eutectoid steel was used as reference. All material used was stress-relieved by the manufacture before machining. Basic material characteristics are presented in Table 1.

A calibrated load cell was used during uniaxial testing with strain gauges attached on the backside of the sample, non-diffracting side. With the strain 
Table 1 Basic characteristics of material studied

\begin{tabular}{llllll}
\hline Graphite type & $\sigma_{\mathrm{ys}}(\mathrm{MPa})$ & UTS $(\mathrm{MPa})$ & Elongation $(\%)$ & Pearlite matrix content $(\%)$ & Graphite area fraction $(\%)$ \\
\hline Flake & - & 290 & $<1$ & 100 & 11 \\
Vermicular & 150 & 420 & $2-4$ & 90 & 11 \\
Spheroidal & 510 & 600 & 10 & 0 & 9.5 \\
\hline
\end{tabular}

gauges, it is possible to detect a linear elastic behaviour, necessary for a proper evaluation of the XEC. For the four-point bending test rig, only strain gauges were used inside the X-ray machine, since no load cell could be used. Instead, the applied stress versus strain curve was determined by inserting the small test rig in a Instron 5582 tension/compression testing machine, where the load was recorded by the Instron load cell and the strain was determined by the strain gauges attached on the non-diffracting side of the four-point bending specimens. In this way, it is possible to determine the linear elastic behaviour.

$X$-ray measurements were taken using a four-circle goniometer Seifert $X$-ray machine, equipped with a $\mathrm{Cr}$ tube. Evaluation of RS was conducted using the $\sin ^{2} \psi$ method [1] with the $\alpha$-Fe $\{211\}$ diffraction peak, at $2 \theta \approx 156.5^{\circ}$, initially by using the theoretical XEC of $1 / 2 s_{2}=5.81 \times 10^{-6} \mathrm{MPa}^{-1}$. A ø 2-mm collimator was used. Peak position was calculated using a double pseudo-Voigt curve fit. Equidistant $\sin ^{2} \psi$ values ranging between $\pm 55^{\circ}$ were used.

Uniaxial test specimens measuring $3 \times 8 \times 50 \mathrm{~mm}$ were preloaded in a the Instron 5582 machine using 15 triangular cycles and a load rate of $3 \mathrm{kN} / \mathrm{min}$, with a minimum load of $0.1 \mathrm{kN}$. The maximum load differs for the three cast iron specimens, approximately $50 \%$ of the tensile strength for flake and vermicular graphite iron, and $75 \%$ of the yield strength for spheroidal graphite iron. Four-point bending specimens measuring $7 \times 14 \times 125 \mathrm{~mm}$ were cyclically preloaded with 10-15 cycles directly in the fourpoint bending rig. The preloading level was chosen to be in the range of the materials fatigue strength.

Calculating the slope of an XRD stress versus applied stress curve gives a ratio of how much the theoretical XEC $1 / 2 s_{2}$ needs to be modified. This modification yields an effective XEC.

For microstructural investigation, scanning electron microscopy (SEM) techniques such as electron backscatter diffraction (EBSD) and electron channelling contrast imaging (ECCI) $[6,7]$ were used in a
Hitachi SU-70 field emission gun scanning electron microscope. The EBSD analysis was conducted using $1 \mu \mathrm{m}$ step size; a more detailed description of the setup is given in [8].

\section{Results}

As-cast microstructure $(\mathrm{a}-\mathrm{c})$ and orientation imaging maps $(\mathrm{d}-\mathrm{f})$ of the three cast iron specimens are illustrated in Fig. 2, where the flake graphite iron exhibits a fully pearlitic matrix with a grain size of $60 \pm 20 \mu \mathrm{m}$ and a flake length of $\sim 100 \mu \mathrm{m}$. Grain size of the vermicular graphite iron was $40 \pm 30 \mu \mathrm{m}$, of which $90 \%$ of the grains are fully pearlitic and $10 \%$ of the grains are fully ferritic. A negligible amount of spherical graphite's could be found in the vermicular graphite iron. The spherical graphite iron had a fully ferritic matrix, with a grain size of $35 \pm 10 \mu \mathrm{m}$ and nodule size of $\sim 10 \mu \mathrm{m}$.

The dependence of $d_{\varphi \varphi}$ versus $\sin ^{2} \psi$ at different loads is shown in Fig. 3, where the small points of intersection seen for all materials tested display good repeatability, accuracy, and reliability in measuring

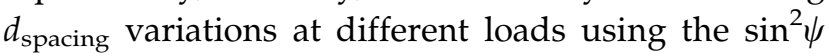
method. The intersection point of the curves also corresponds to the strain-free direction, which is independent of stress state.

Figure 4a shows how measured XRD stresses correspond to applied stress for the three cast iron specimens in uniaxial tension testing. A comparison of XRD stress versus $\varepsilon$ and applied stress versus $\varepsilon$ for the four-point bending data is illustrated in Fig. $4 \mathrm{~b}$, where empty markers represent XRD data and solid markers the Instron data. Linear fits were done in order to estimate the linear relationship, using the $R^{2}$ value as a measure of linearity. Slopes of the linear fits and corresponding $R^{2}$ values for the cast iron are tabulated in Table 2. The calculated effective XEC are tabulated in Table 3, showing that the type of testing method does not seem to influence the results. The 

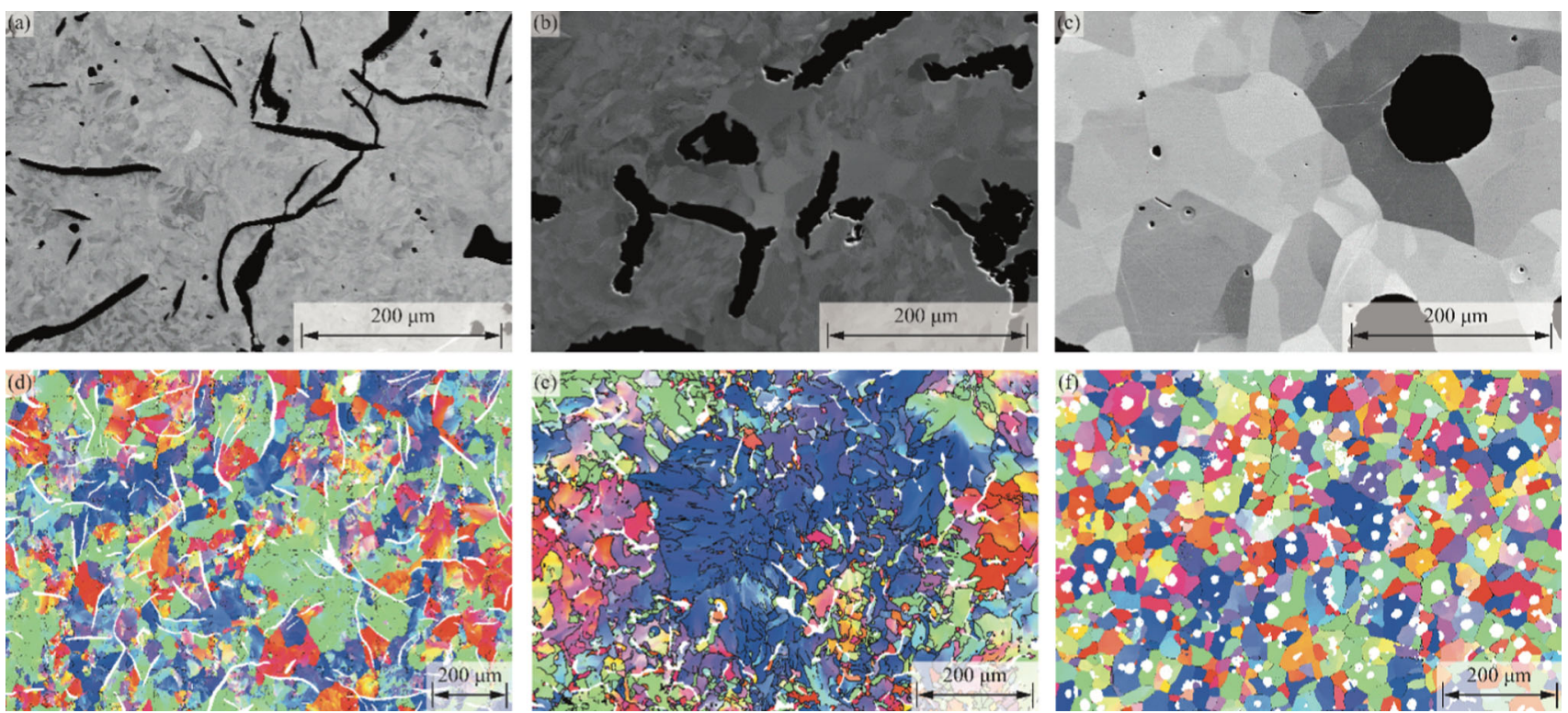

Figure 2 Microstructural morphology of $\mathbf{a}$ flake, $\mathbf{b}$ vermicular, and $\mathbf{c}$ spheroidal graphite iron, and orientation imaging maps of $\mathbf{d}$ flake, e vermicular, and $\mathbf{f}$ spheroidal graphite iron.

(a)

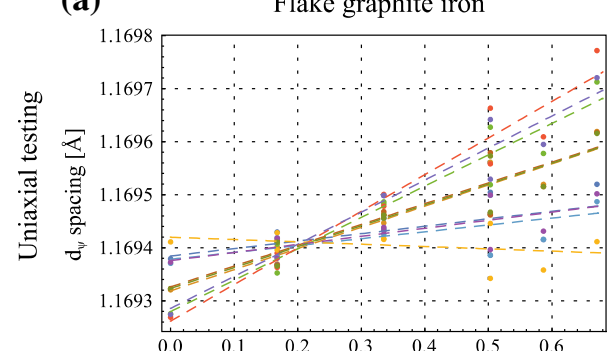

(d)
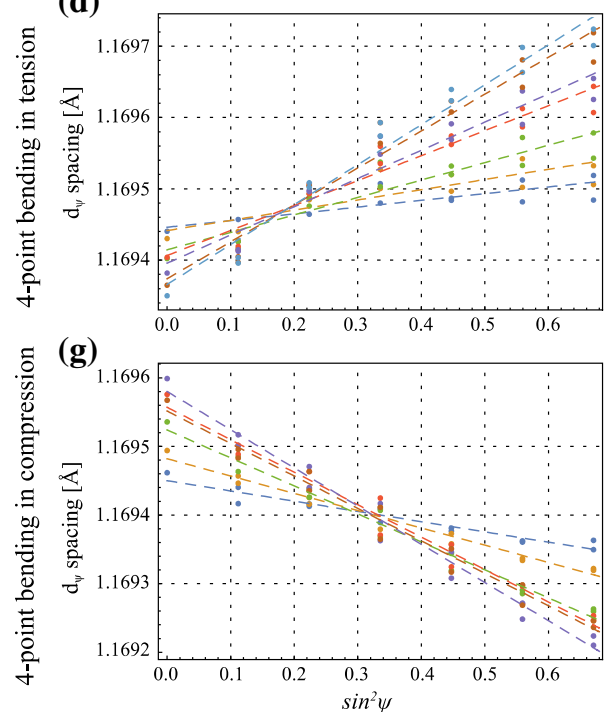

(b)

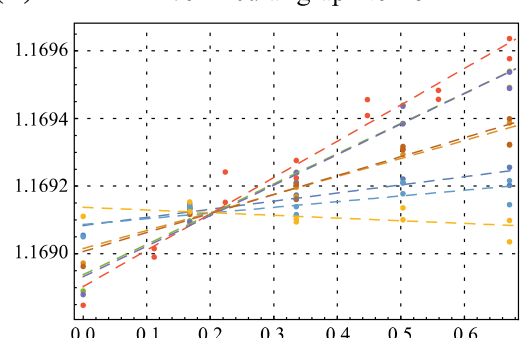

(e)

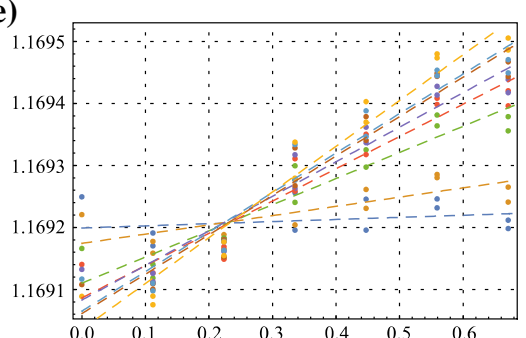

(h)

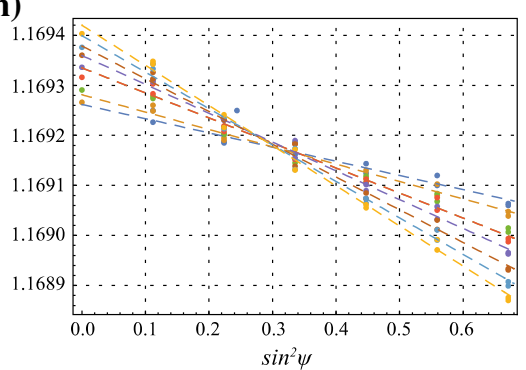

(c)

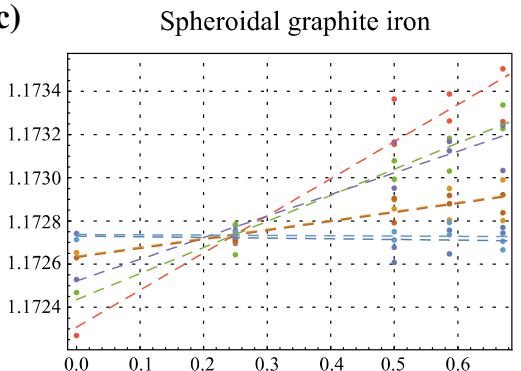

(f)

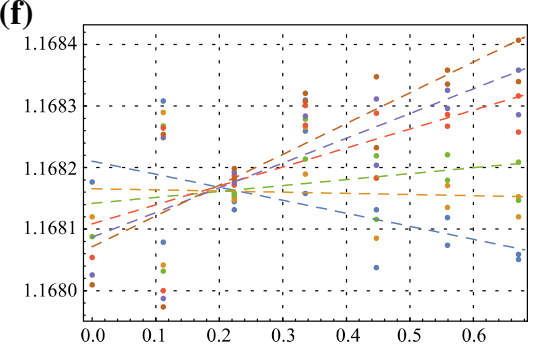

(i)

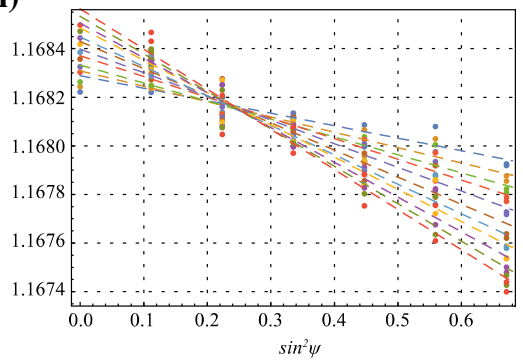

Figure 3 The $d_{\varphi \psi}$ versus $\sin ^{2} \psi$ at different loads for $\mathbf{a}-\mathbf{c}$ uniaxial testing, $\mathbf{d}-\mathbf{f}$ four-point bending in tension, and $\mathbf{g}-\mathbf{i}$ four-point bending in compression for flake, vermicular, and spheroidal graphite iron, respectively. 
(a)

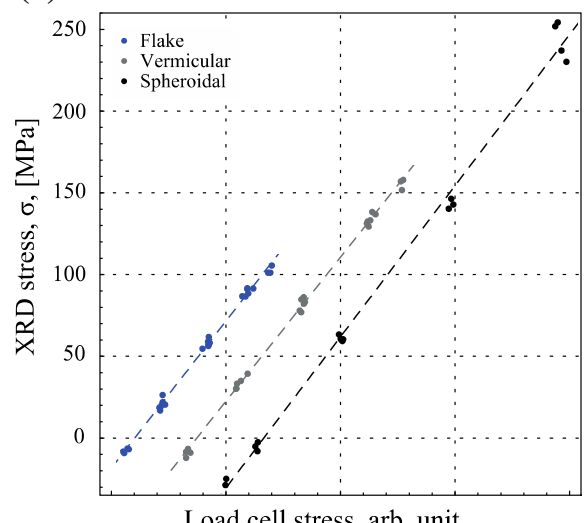

Load cell stress, arb. unit

(b)

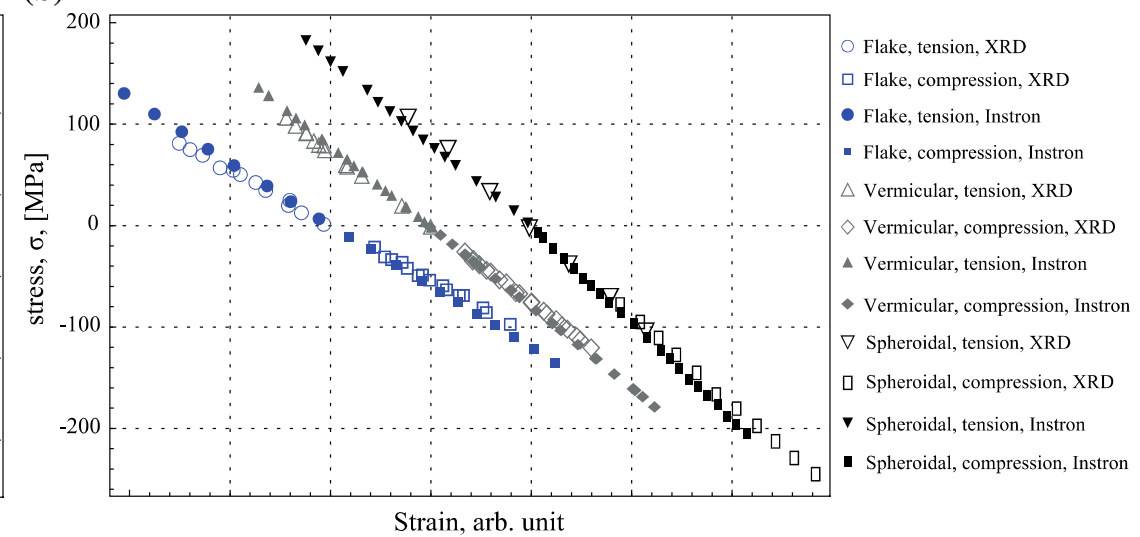

Figure 4 From left to right are data for flake, vermicular, and spheroidal graphite iron, respectively. a XRD stresses plotted against the applied stress for the uniaxial tension configuration.

Every dashed support line on the $x$-axis represents $100 \mathrm{MPa}$. b Comparison of Instron and XRD load versus strain data for fourpoint bending. Every line on the $x$-axis represents $0.05 \%$ strain.

Table 2 Curve-fitting parameters for uniaxial tension testing as well as the observed Young's modulus from X-ray machine and Instron together with their respective linear fit parameter for the materials and test method used

\begin{tabular}{|c|c|c|c|c|c|c|}
\hline \multirow[t]{2}{*}{ Test method } & \multicolumn{2}{|l|}{ Flake } & \multicolumn{2}{|l|}{ Vermicular } & \multicolumn{2}{|l|}{ Spheroidal } \\
\hline & XRD & Instron & XRD & Instron & XRD & Instron \\
\hline Uniaxial tension & $\begin{array}{l}y=0.898 x \\
R^{2}=0.996\end{array}$ & - & $\begin{array}{l}y=0.882 x \\
R^{2}=0.998\end{array}$ & - & $\begin{array}{l}y=0.925 x \\
R^{2}=0.993\end{array}$ & - \\
\hline Four-point bending in tension & $\begin{array}{l}110 \mathrm{GPa} \\
R^{2}=0.993\end{array}$ & $\begin{array}{l}127 \mathrm{GPa} \\
R^{2}=1.000\end{array}$ & $\begin{array}{l}149 \mathrm{GPa} \\
R^{2}=0.998\end{array}$ & $\begin{array}{l}160 \mathrm{GPa} \\
R^{2}=1.000\end{array}$ & $\begin{array}{l}179 \mathrm{GPa} \\
R^{2}=0.999\end{array}$ & $\begin{array}{l}163 \mathrm{GPa} \\
R^{2}=1.000\end{array}$ \\
\hline Four-point bending in compression & $\begin{array}{l}109 \mathrm{GPa} \\
R^{2}=0.995\end{array}$ & $\begin{array}{l}121 \mathrm{GPa} \\
R^{2}=1.000\end{array}$ & $\begin{array}{l}147 \mathrm{GPa} \\
R^{2}=0.999\end{array}$ & $\begin{array}{l}158 \mathrm{GPa} \\
R^{2}=1.000\end{array}$ & $\begin{array}{l}174 \mathrm{GPa} \\
R^{2}=0.999\end{array}$ & $\begin{array}{l}190 \mathrm{GPa} \\
R^{2}=1.000\end{array}$ \\
\hline
\end{tabular}

Table 3 Determined effective XEC $\left(1 / 2 s_{2}\right)$ for the $\alpha$-Fe $\{211\}$ given in $\times 10^{-6} \mathrm{MPa}^{-1}$

\begin{tabular}{llllll}
\hline Test method & $\begin{array}{l}\text { Flake graphite } \\
\text { iron }\end{array}$ & $\begin{array}{l}\text { Vermicular graphite } \\
\text { iron }\end{array}$ & $\begin{array}{l}\text { Spheroidal graphite } \\
\text { iron }\end{array}$ & $\begin{array}{l}\text { Pearlitic } \\
\text { steel }\end{array}$ & $\begin{array}{l}\text { Theoretical value } \\
\text { (Voigt) [1] }\end{array}$ \\
\hline Uniaxial tension & $5.22 \pm 0.05$ & $5.12 \pm 0,05$ & $5.37 \pm 0.05$ & - & 5.81 \\
$\begin{array}{l}\text { Four-point bending in tension } \\
\text { Four-point bending in } \\
\text { compression }\end{array}$ & $5.03 \pm 0.05$ & $5.41 \pm 0.05$ & $6.38 \pm 0.05$ & $6.00 \pm 0.05$ & 5.81 \\
\hline
\end{tabular}

calculated effective XEC of the pearlitic steel is well in line with the literature $[3,5,9,10]$.

\section{Discussion}

Graphite morphology and matrices are illustrated in Fig. 2a-c for the three cast iron specimens. EBSD analysis, shown in Fig. 2d-f, was conducted enabling grain size determination. The average grain size for the three cast iron specimens was $<80 \mu \mathrm{m}$. A 2-mm collimator means that the spot size would have a diameter of at least $2 \mathrm{~mm}$ not accounting for beam divergence. Thus, the irradiated area is roughly $3.1 \mathrm{~mm}^{2}$ in size. To get a reliable RS measurement, the gauge volume should comprise at least 50 grains. Assuming a grain size of $80 \mu \mathrm{m}$ results in approximately 600 grains within the gauge volume and yields more than enough grains within the diffraction spot for accurate RS measurements. 
Maximum applied load during XEC calibration, according to ASTM E 1426-98, should be equivalent to $75 \%$ of the yield strength. Due to the nonlinear elastic behaviour of cast iron, e.g. flake and vermicular graphite iron, the guidelines given in the standard are not easily fulfilled. To make cast iron appear more like a linear elastic material, cyclic preloading is implemented. Preloading is used to initiate microcracks homogeneously throughout the testing volume. After initiation, microcracks will propagate slowly (depending on load level), exhibiting a more "steadystate" hysteresis loop. Since preloading results in a more linear elastic behaviour, the guidelines given in ASTM E 1426-98 will be more fulfilled. The change in strain behaviour is of less importance during preloading. Since it is the linear elastic area, which is of interest, only two cycles were needed to achieve a linear elastic behaviour. However, according to ASTM E 1426-98, XEC should be determined utilizing several load cycles, to ensure that the effective XEC do not vary as an effect of cycling. A total of 10-15 preloading cycles were implemented, instead of analysing the effective XEC for each load cycle until the XEC did not change between cycles. The amount of damage introduced in the material via cyclic preloading was not significant because no change could be seen in the linear elastic response between load cycle two and ten. By doing this, cast iron can be treated as a linear elastic material, thereby reducing errors in effective XEC determination. The preloading level was chosen to be in the range of the materials fatigue strength; thereby we can assume that the amount of microcracks is limited.

Little and no clear information regarding specimen surface integrity is reported in the literature. Surface integrity can affect the effective XEC as shown in [5]. Careful grinding and polishing of the test specimens were conducted. By grinding and polishing, the effect of strain hardening is diminished giving a more correct effective bulk XEC parameter. Fundamental errors $[1,3,4]$ such as strain gradients within the gauge volume are also reduced by grinding and polishing. Post-polishing RS measurements were taken to establish that a stress-free gauge volume had been achieved. However, this was not fully achieved for the spheroidal graphite iron subjected to fourpoint bending in tension.

Normally it is assumed that the same gauge volume has been used. This can be controlled by looking at how well the $d_{\text {spacing }}$ versus $\sin ^{2} \psi$ linear fits intersect. Figure 3 illustrates well defined intersecting points for all cast iron and methods used. This can be interpreted that more or less the same gauge volume was measured every time. Since the material is inhomogeneous, using the same gauge volume increases the RS versus applied load linearity. The linear relationship between RS and applied load is illustrated in Fig. 4 and tabulated in Table 2. If a correct XEC value was used, the slope would be one; if not, the correction factor would be the slope.

In order to get an accurate applied load value for the four-point bending, the four-point bending rig used in the XRD machine was transferred to a servo electric Instron 5582 tension/compression testing machine with a calibrated load cell. By doing this, we were able to compare XRD stress versus strain with that measured using a conventional tension/compression testing machine, seen in Fig. $4 \mathrm{~b}$. The slopes of the linear fits for the XRD and Instron data would be the same if the correct XEC value was used. If not, a correction factor can be derived by comparing the Young's modulus retrieved from the XRD data with the Instron data. The different Young's modulus values used are listed in Table 2 together with linear least-square fitting parameter.

Derived XEC values are compared in Table 3. Flake and vermicular graphite iron show a lower effective XEC value than the theoretical value. Flake and spheroidal graphite iron show the same behaviour regarding the effective $\mathrm{XEC}$ variations for the uniaxial and four-point bending in compression. Vermicular graphite iron showed the same behaviour but for the four-point bending in tension and compression. In a perfect world, we could assume that, regardless of testing method, the effective XEC would be the same for each material.

For the flake graphite iron, there was a small difference in effective XEC when comparing the three tested methods. Four-point bending in tension showed the smallest derived value. This is most likely due to a bending-induced movement of the specimen. Flake graphite iron exhibits the most nonlinear elastic behaviour of the three different cast iron specimens; despite this, it shows the smallest variation in effective XEC of the three cast iron specimens. This gives rise to the expectation that the effective XEC of vermicular and spheroidal graphite iron would deviate less than that of the flake graphite iron. This means that the same effective XEC should be derived regardless of testing method. 
Two different castings were used for manufacturing vermicular graphite iron test specimens. One casting was used for the uniaxial testing specimen and the second casting for the specimens subjected to four-point bending. As seen in Table 3, the effective XEC overlap each other for the four-point bending specimens. A small difference in effective XEC can be seen between the two castings. The most probable explanation for the small difference would be different chemical compositions and microstructural morphology, e.g. graphite shape and size.

The value derived from four-point bending in tension for spheroidal graphite iron differs from the uniaxial tension and four-point bending in compression testing. All spheroidal graphite iron specimens originate from the same casting; consequently, they have the same chemical composition. After fourpoint bending in tension, the specimen showed more compressive RS and a larger FWHM value than the specimens used for uniaxial tension and four-point bending in compression. Strain hardening induced by machining is the most probable explanation for the deviation of effective XEC.

The derived effective XEC value for the pearlitic steel was well in line with that reported in the literature $[3,5,9-11]$. This validates that the experiments and calculations were performed correctly.

Determining correct effective XEC of cast iron should be done with care. Due to possible errors such as changes in the hysteresis loop, gauge volume, bending translation, chemical composition, and strain hardening, correct effective XEC are needed in order to validate models and simulations. More research investigating surface integrity effects as well as steep strain gradients is needed.

\section{Conclusions}

- The same effective XEC should be derived regardless of testing method.

- The following error sources should be considered when deriving effective XEC: changes in the hysteresis loop, gauge volume, bending translation, chemical composition, and strain hardening.

- Cyclic preloading is important to perform until the hysteresis loop reaches a "steady-state" condition, due to the nonlinear elastic behaviour of cast iron.
- The derived effective XEC values are lower than the theoretical.

- All three cast iron specimens exhibited similar effective XEC value.

\section{Acknowledgements}

The authors would like to thank Agora Materiae, graduate school, the Swedish Government Strategic Research Area in Materials Science on Functional Materials at Linköping University (Faculty Grant SFO-Mat-LiU \#2009-00971), Vinnova FFI, Scania, and Volvo Trucks for financial support.

\section{Compliance with ethical standards}

Conflict of interest The authors declare that they have no conflict of interest.

Open Access This article is distributed under the terms of the Creative Commons Attribution 4.0 International License (http://creativecommons.org/ licenses/by/4.0/), which permits use, duplication, adaptation, distribution and reproduction in any medium or format, as long as you give appropriate credit to the original author(s) and the source, provide a link to the Creative Commons license and indicate if changes were made.

\section{References}

[1] Noyan IC, Cohan JB (1987) Residual stress, 1st edn. doi:10. 1007/978-1-4613-9570-6

[2] Hilley ME, Larson JA, Jatczak CF, Ricklefs RE (1971) Residual stress measurement by X-ray diffraction-SAE J784a. Society of Automotive Engineers INC, Warrendale

[3] Hauk V, Behnken H (1997) Structural and residual stress analysis by nondestructive methods: evaluation, application, assessment. Elsevier, Amsterdam

[4] Lu J, for Experimental Mechanics (US) S (1996) Handbook of measurement of residual stresses. Fairmont Press, New York

[5] Hauk V, Wolfsteig U (1976) Röntgenographische Elastizitätskonstanten. J heat Treat Mater 31:38-42

[6] Kamaladasa RJ, Picard YN (2010) Basic principles and application of electron channeling in a scanning electron microscope for dislocation analysis. Microsc Sci Technol Appl Edu 3:1583-1590 
[7] Gutierrez-Urrutia I, Zaefferer S, Raabe D (2009) Electron channeling contrast imaging of twins and dislocations in twinning-induced plasticity steels under controlled diffraction conditions in a scanning electron microscope. Scr Mater 61:737-740. doi:10.1016/j.scriptamat.2009.06.018

[8] Lundberg M, Saarimäki J, Peng RL, Moverare JJ (2017) Residual stresses in uniaxial cyclic loaded pearlitic lamellar graphite iron. Mater Res Proc 2:67-72. doi:10.21741/ 9781945291173-12
[9] Marion RH, Cohen JB (1976) The need for experimentally determined X-ray elastic constants. Evanston, IL

[10] Prevey PS (1977) A method of determining the elastic properties of alloys in selected crystallographic directions for X-ray diffraction residual stress measurement. Adv X Ray Anal 20:345-354

[11] Prevéy PS (1986) X-ray diffraction residual stress techniques. Met Handbook 10 Met Park 380-392. doi:10.1361/ asmhba0001761 